\title{
CREACIÓN COLECTIVA
}

AUDIOVISUAL Y

CULTURA

COLABORATIVA

ON-LINE

\section{Proyectos y estrategias}

\section{Jordi Alberich Pascual}

\section{Profesor Titular de Universidad}

Facultad de Comunicación y Documentación. Universidad de Granada. Campus Cartuja, s/n. 18012 Granada. Tlf. 958241963 Email: jalberich@ugr.es Web: http://www.jordialberich.info

\section{Antoni Roig Telo}

Profesor y Director del Programa de

\section{Comunicación Audiovisual}

Estudios de Ciencias de la Información y la Comunicación. Universitat Oberta de Catalunya. Rambla del Poblenou, 156. 08018 Barcelona (España) - Email: aroigt@uoc.edu

\section{Resumen}

El presente artículo analiza el desarrollo creciente de proyectos audiovisuales de creación colectiva en y a través de Internet. Para ello, se exploran en primer lugar las implica-
Palabras clave

Creación colectiva, cultura colaborativa, software libre audiovisual, Cine Open Source

Key Words

Collective creation, collaborative culture, media free software, Open Source Cinema

\section{Abstract}

This article discusses the growing development of media projects of collective creation in and through the Internet. This will first explore the implications for redefining the traditional author-role that enable interactive multimedia systems, as well as its relationship with work strategies in collaborative network. After that, we focus our attention on the use and development of media free and open source software and resources, as a paradigmatic example of the growing vitality of a collaborative culture in contemporary media creation and production fields. Finally, the article concludes by setting the basic identifying keys of three different approaches in the examples of collective media creation analyzed in the course of our investigation. 
ciones para la redefinición de la función-autor tradicional que posibilitan los sistemas interactivos multimedia, así como su vinculación con estrategias de trabajo colaborativo en red. A continuación, centramos nuestra atención en el uso y desarrollo de recursos de software libre audiovisual, como ejemplo paradigmático de la vitalidad de una creciente cultura colaborativa en el ámbito audiovisual contemporáneo. Finalmente, el artículo concluye estableciendo las claves identificativas básicas de tres aproximaciones diferenciadas a las tareas y estrategias de trabajo implicadas en los proyectos de creación colectiva audiovisual analizados en el curso de nuestra investigación.

\section{Introducción}

En la era contemporánea, la noción de red ocupa un lugar destacado en la conceptualización de gran parte de los fenómenos sociales y comunicativos que nos rodean, habiendo llegado a convertirse en modelo y a la vez paradigma para la comprensión del desarrollo presente de la actual era de la información. Internet aparece en la base de un amplio conjunto de hechos y de fenómenos revolucionarios de nuestro hoy, de forma destacada, de la intensa redefinición del papel y de las funciones tradicionalmente pasivas del público de los medios de comunicación.

La acción comunicativa en y a través de los nuevos medios de comunicación digital, ofrece contenidos típicamente flexibles e inestables, de ubicuidad asíncrona, desmaterializados y/o desterritorializados, así como -entre otras variables revolucionarias posibles- radicalmente accesibles para usuarios distantes, liberados del aquí y ahora físico y presencial (Echeverría, 1999). La digitalización creciente de procesos y productos comunicativos a lo largo de la últi- ma década está implicando importantes cambios no sólo en los contenidos comunicativos, sino también y muy especialmente, en las posibilidades de uso, participación $\mathrm{y}$ creación colaborativa que posibilitan.

Un amplio abanico de las producciones audiovisuales digitales contemporáneas no se construyen ya de forma individualista y/o solipsista, sino de forma colectiva $y$ plural. Surgen de planteamientos creativos basados en la participación en la producción de la obra, y que los medios digitales posibilitan como nunca antes (Jenkins, 2006). Numerosos grupos y colectivos conectados on-line implementan a diario una autoría compartida, fruto de la interrelación de sistemas y contenidos de procedencia y naturaleza diversa, propia de la red, una nueva forma de entender la acción comunicativa en la que el creador deja de ser único y solitario, para pasar a convertirse en un autor plural, trabajando hermanado con una colectividad de co-participantes del acto creativo. 


\section{Objetivos}

El presente artículo persigue satisfacer los siguientes objetivos específicos:

- Valorar el alcance e importancia del desarrollo de proyectos de creación colectiva audiovisual en la cultura digital contemporánea.

- Analizar y destacar la redefinición de la función-autor tradicional en los entornos y sistemas interactivos multimedia.
- Establecer conexiones y afinidades conceptuales entre desarrollo de recursos de software libre audiovisual y la cultura colaborativa en la era de la información.

- Identificar y discriminar diferentes modelos y estrategias de aproximación posible en la creación colectiva audiovisual on-line contemporánea.

\section{Metodología}

El proceso metodológico desarrollado en la presente investigación ha partido de la exploración y consulta bibliográfica intensiva de fuentes de información de interés en relación con a) la redefinición de la categoría de autor en la cultura contemporánea, así como con b) la redefinición de los sistemas y procesos de creación y producción audiovisual en la era de la información. Tras la lectura y análisis crítica de ambas fuentes, se ha procedido a interrelacionar conceptualmente uno y otro campo, con el fin de mostrar sus afinidades y sinergias compartidas.

A continuación, con la toma como estudio de caso paradigmático del territorio discursivo y performativo propio del movimiento del Software Libre, hemos desarrollado la búsqueda, selección y análisis de proyectos destacados de creación colectiva audiovisual 'de código abierto' afines, desarrollados preferentemente en los últimos cinco años (2002-2007).

Finalmente, el análisis crítico cualitativo del conjunto de obras y proyectos estudiados, nos ha permitido identificar y discriminar tres modelos conceptuales de aproximación, con claves básicas propias y diferenciadas entre sí, en el conjunto de las estrategias de creación colectiva contemporánea on-line para el ámbito audiovisual, y que presentamos a modo de conclusiones de nuestra investigación en curso. 


\section{El autor en los sistemas multimedia}

Como en un taller medieval, en el que distintos artesanos producían colectivamente una determinada obra, también los nuevos talleres on-line -que la denominada Web 2.0 ejemplifica sobremanera- posibilitan de modo creciente una producción y autoría compartida, fruto de la interrelación de usuarios, soportes y contenidos de procedencia y naturaleza diversa, propia de los sistemas multimedia. Características tan distintivas y propias de los entornos digitales como hipertextualidad e interactividad al mismo tiempo tecnológicas y performativas-, fagocitan y promueven la reconfiguración tradicional de la categoría de autor. De un modo revolucionario, los sistemas multimedia posibilitan, y al mismo tiempo potencian, la creación y la producción de obras grupales.

La naturaleza del hipertexto, consistente en fragmentar los textos en unidades aisladas, favorece la construcción compartida de obras en manos de sus diversos usuarios. "El hipertexto reconfigura -reescribe- al autor de varias maneras evidentes. La figura del escritor en hipertexto se acerca a la del lector, aunque no se funda completamente con ella; las funciones del escritor y del lector se entrelazan más estrechamente que en cualquier otro momento". (Landow, 1992: 20). El ejemplo de la literatura electrónica y del conjunto de las narrativas interactivas así lo evidencian históricamente. En éstas, los lectores eligen su propio recorrido y pueden llegar a leer potencialmente textos propios, sin llegar a percibir en muchos casos el texto completo original, sino únicamente lo que han obtenido a raíz de sus elecciones y el itinerario desarrollado.

Por entorno y contexto tecnológico, en el proceso de comunicación multimedia la respuesta y la interacción del usuario se convierten, de hecho, en el objetivo de la totalidad del sistema. En substitución de la tradicional recepción pasiva y lineal que requería la producción estética anterior al desarrollo de las tecnologías de la información, el usuario se transforma ahora en un co-jugador clave para la concreción final del escenario multilineal propuesto. En los sistemas multimedia la autoría se comparte. La labor de autoría en los entornos digitales consiste muchas veces no ya en la creación de un conjunto cerrado en si mismo, sino en la creación de un sistema de posibilidades participativas, promoviendo así que el autor en los sistemas multimedia devenga una figura doble, compartida por creadores y usuarios. "Los entornos digitales hipertextuales crean un lector/usuario/receptor activo y hasta entrometido, que contribuye a la convergencia entre las actividades tradicionales del autor y del lector; al hacerlo, invaden las prerrogativas del autor, quitándole algunas para otorgárselas al lector" (Landow, 1992: 24). 
El usuario del sistema participa así de una autoría derivada, en tanto que determina mediante su interacción una construcción virtual concreta inexistente como tal previamente. En los sistemas multimedia la autoría se comparte entre el autor (primaria) y el usuario (derivada). El autor de un sistema interactivo multimedia debe posibilitar y delegar la concreción de opciones e itinerarios al usuario potencial del sistema planteado. "El autor de narrativa electrónica es un coreógrafo que proporciona los ritmos, el contexto, y los pasos que se pueden bailar. El usuario, ya sea navegador, protagonista, explorador o constructor, utiliza este repertorio de pasos y ritmos posibles para improvisar un baile entre las muchas posibilidades que el autor ha preparado". (Murray, 1998: 127). Pese a que no resulte válido llegar a identificar el valor de ambas autorías, el proceso creativo se desarrolla en múltiples oportunidades como una autoría abierta, capaz de delegar su concreción final en el usuario, así como -muy especialmente- de posibilitar su participación.

Las nuevas herramientas y recursos multimedia, hipertextuales e interactivos, que fracturan la linealidad propia de los mode- los analógicos, promueven una definición de la acción comunicativa contemporánea calidoscópica (Murray, 1998: 131), abierta, que facilita la participación de sus usuarios de muchas y variadas formas. Internet deviene en la actualidad el paradigma de un entorno social, tecnológico y creativo dónde no tiene ya sentido pensar exclusivamente la comunicación mediada en clave unidireccional, de uno a muchos, donde las barreras entre producción y consumo se diluyen, y donde conceptos como espectador o audiencia se nos hacen insuficientes. En la producción estética multimedia, el usuario ocupa en la actualidad un lugar y una importancia decisiva en las tareas previas de guionización y conceptualización de las obras. En las interfaces gráficas hay que tener previstas y tratadas las diferentes respuestas posibles, así como las numerosas trayectorias de navegación y formas de acceder a los contenidos difundidos. La estética digital ofrece obras estructuradas para la participación activa del usuario en su implementación y definición final. El hipertexto y el conjunto de la acción comunicativa multimedia necesita de la intervención e interacción del usuario: no tiene sentido sin él. 


\section{Creación colectiva on-line y networking}

"La creación colectiva es el contenido más revolucionario de la cultura digital, aquello que mejor facilita su distinción de la cultura tradicional es la posibilidad de construir una cultura realmente colectiva”. (Casacuberta, 2003: 11).

La expresión Networking (hacer red) es su síntesis conceptual. Consiste en el desarrollo de prácticas creativas participativas y colaborativas entendidas a la vez como actividad social y cultural, y como forma de gestión y producción descentralizada, rompiendo así con las jerarquías y los modelos dominantes en los sistemas culturales tradicionales y de poder.

Las estrategias creativas apropiacionistas y de net.art resultan pioneras y emblématicas de esta colectivización creativa propia de Internet. Ya desde mediados de los años 90' del siglo pasado, son ejemplos habituales de networking la (1) creación de foros y BBS (bulletin board system, 'sistema de tablón de anuncios'), con redes de afinidad vinculadas a su vez a plataformas electrónicas más amplias: plataformas web de organizaciones sociales, políticas y de información independiente, la (2) distribución de información sobre determinados hechos $\mathrm{o}$ acciones entre personas que no tienen ningún acceso a esta información a través de otros medios, como por ejemplo noticias olvidadas por los medios de comunicación corporativos o que han sido ofrecidas tan sólo de forma tendenciosa, o bien las
(3) la reapropiación o el plagio del contenido del determinadas páginas web a fin $\mathrm{y}$ efecto de subvertir su función comercial, cuestionando así la política de derechos de autor y otras restricciones habituales para la expresión cultural en el mundo comercialprivativo. Veamos un ejemplo. The File Room, una obra audiovisual digital iniciada el año 1994 por Antoni Muntadas y que sigue activa actualmente resulta paradigmática del compromiso social y de la ética colaborativa señalada en la acción comunicativa en red.

The File Room consiste en un archivo audiovisual accesible y colaborativo on-line que crece día a día con nuevos datos sobre la censura artística y cultural que se practica en nuestro planeta. Cualquier persona conectada a la Red tiene la posibilidad de acceder a las imágenes prohibidas, a la información recopilada sobre los autores y sus circunstancias, así como de proponer e incorporar participativamente nuevas obras y casos.

"Desde su inicio, este proyecto ha tenido en cuenta las cuestiones suscitadas por la interactividad, la audiencia y el rol social del arte. Mientras se estaba elaborando The File Room, los problemas planteados por las nuevas tecnologías respeto a la censura, las fuentes de la obra, su accesibilidad, su lenguaje, su traducción, su control y sus motivaciones fueron buscadas: todos estos problemas son a su vez elementos constitutivos $y$ 
consecuencias de la obra y de su temática." (Muntadas, 1995).

Para la acción comunicativa audiovisual, Internet y la cultura digital que conlleva, posibilita una visión alternativa a los esquemas e ideas tradicionales sobre el desarrollo personal y profesional de los creadores audiovisuales, circunscrito a menudo en exceso a una concepción demasiada rígida, normativa y cerrada de las posibilidades del sector audiovisual. En el ámbito audiovisual existe una visión idealizada de un autor que adquiere proyección a través de proyectos personales de envergadura o de su incorporación prioritaria y exclusiva a alguna de las principales empresas productoras o distribuidoras. Ciertamente, se trata de una expectativa totalmente razonable y real, pero no la única. Hace falta tener en cuenta otras posibilidades para la producción y la comercialización audiovisual en todas sus vertientes y que cada vez son más factibles gracias a las posibilidades de la comunicación en red. Hace pocos años era casi impensable que un estudiante pudiera diseñar y experimentar los elementos básicos de una superproducción desde su propia casa y conseguir posteriormente el espaldarazo de una gran productora ${ }^{1}$, o que grupos de fans llegaran a producir y difundir sus propias versiones de sus referentes audiovisuales, de forma modesta pero con un nivel de creatividad y calidad técnica sorprendente. Hoy todo esto es posible (y habitual). Internet y el conjunto de la nueva cultura audiovisual digital están redefiniendo el concepto y la relación entre la producción, la distribución, la creación, el uso y el consumo audiovisual.

\section{Software libre audiovisual y cultura colaborativa}

Exprimir todas las manifestaciones y direcciones posibles de la comunicación audiovisual digital tiene en el software libre a uno de de sus mayores aliados, así como su uso y la vitalidad de las comunidades virtuales existentes afines resultan hoy un claro exponente de los procesos de redefinición de roles en el campo audiovisual a los cuales estamos asistiendo. Diariamente nuevos proyectos participativos se añaden, mientras otros se adaptan o cambian en función de nuevos intereses, fruto de la condición radicalmente cambiante del presente de la comunicación audiovisual.

La evolución tecnológica y los procesos de creación y producción de proyectos 'estilo Bazar' (Raymond, 1999) proporcionan nuevas oportunidades para la creación y la difusión audiovisual con un elevado grado de autonomía y de independencia. En el seno del intensivo proceso de cambio y substitución de modelos y de conceptos clave al cual asistimos, la producción de aplicaciones audiovisuales de naturaleza 'libre' vive actualmente una fase de investi- 
gación de sus posibilidades. El activo mundo del software libre fomenta una manera diferente de ver, percibir, vivir y valorar las formas audiovisuales, de señalar las problemáticas y también las oportunidades de las incertidumbres, una manera que ya se asume como propia por parte de las jóvenes generaciones que se (auto) identifican como usuarios de los Media, y ya no como meros receptores de éstos.

En el campo concreto del software audiovisual resulta sin duda difícil -y caro- adaptarse en numerosas ocasiones a las principales soluciones propietarias estándar. Las empresas de software suelen trabajar, incluso en sus soluciones para entornos docentes, con licencias de uso individual y limitado, que suponen un enorme sobrecoste para los estudiantes y usuarios emprendedores ${ }^{2}$. Junto a estas soluciones, la opción por el uso de software libre para la creación y la producción audiovisual permite a los usuarios un mayor grado de adaptación, de creación colectiva, de iniciativa en la configuración y en la definición de la propia herramienta.

La preferencia por la expresión 'software libre' en detrimento de otras cercanas Como 'software de código abierto' o 'software de dominio público' debe asumir implicaciones sociales y políticas de calado para que su uso no resulte baladí. De acuerdo con la caracterización establecida por la misma Free Software Foundation ${ }^{3}$ (la organización internacional creada en 1985 dedicada al desarrollo y la promoción del soft- ware libre), un programa es software libre siempre y cuando los usuarios de éste tengan garantizadas cuatro libertades básicas. A saber, (1) la libertad de ejecutar el programa sea cual sea su propósito, (2) la libertad de estudiar y modificar el programa para ajustarlo a sus necesidades, (3) la libertad de redistribuir copias, ya sea de forma gratuita, ya sea a cambio del pago de un precio, y (4) la libertad de mejorar el programa y luego hacerlo público para el bien de toda la comunidad.

En contra de lo que resulta una acepción errónea habitual, el uso de software libre no implica forzosamente su gratuidad. Cualquier programa libre está disponible para su posterior uso, desarrollo o distribución comercial -siempre y cuando respete las cuatro libertades básicas a las que hemos hecho referencia-. Software libre no quiere decir software gratis, software de precio cero. Debemos evitar interpretar su uso y promoción como una mera cuestión de precio. Es y supone mucho más que eso. El software libre implica, ante todo, fomentar y garantizar que todos los usuarios de un programa tengan la libertad de cooperar con otros al usarlo, y poder así compartir y hacer extensibles sus mejoras al resto de la comunidad, "(su uso) tendría una ventaja social, al permitir a los usuarios cooperar, y una ética, al respetar su libertad" (Stallman, 2004: 31).

Implica asumir de forma plena y coherente una perspectiva comunitaria, una ideología cooperativa y responsable por el bien 
común, así como una ética hacker del trabajo (Himanen, 2001). La apuesta por el software libre conlleva pues trabajar en aras de una sociedad donde la información esté verdaderamente a disposición de sus ciudadanos, resultando para estos usable y accesible, facilitando y promocionando el desarrollo de programas que la gente pueda adaptar, mejorar y compartir, y ya no solamente ejecutar.

En afinidad con la perspectiva ética comunitaria que domina el desarrollo del conjunto del software libre, el desarrollo de proyectos audiovisuales libres y/o de código abierto, supone y persigue fomentar $y$ garantizar la posibilidad de participación colectiva en proyectos de creación audiovisual, así como la posibilidad de compartir y hacer uso de los contenidos audiovisuales resultantes por parte del conjunto de la sociedad, desde la creencia ética común y compartida de que los contenidos audiovi- suales deben ser en nuestra sociedad red de los usuarios y para los usuarios.

La creación y producción de proyectos audiovisuales colaborativos implica así favorecer el fortalecimiento de una cultura libre, en la que se asuma de forma plena y coherente una perspectiva cooperativa $y$ responsable por el bien cultural común, de uso, acceso y dominio público, en afinidad con la inspiración de las propias herramientas libres que han permitido, favorecido o inspirado su creación ${ }^{4}$. Esto es, trabajar en aras de una sociedad donde la información y los contenidos de naturaleza audiovisual estén verdaderamente a disposición de sus ciudadanos, resultando para estos plenamente usables y accesibles, sin las tan habituales limitaciones y restricciones de uso a las que la cultura audiovisual comercial nos tiene hoy (sic) tan habituados (Lessig, 2004).

\section{Proyectos y estrategias de creación y producción audiovisual colaborativa}

Las múltiples posibilidades que ofrece el software libre para la creación y la producción audiovisual son el exponente de una corriente cultural más amplia, que se caracteriza por facilitar una mayor autonomía a creadores independientes, al rebajarse las barreras de entrada a la producción de contenidos, así como también por proporcionar una mayor capacidad de acceso a los públicos. Disponemos de infinidad de ejemplos de este último fenómeno día a día en YouTube y sitios similares, pero la mezcla de sorpresa y familiaridad con la que podemos observar la proliferación de lo audiovisual en Internet no debería impedirnos valorar su diversidad. A continuación, se precisan tres modelos y estrategias distintas de creación audiovisual colectiva, 
tres implementaciones de una creación y producción audiovisual plural en las que el software libre y otras herramientas y plataformas colaborativas juegan un papel fundamental dentro de un entorno de creación participativa en continua expansión.

\subsection{Cine Open Source}

Uno de los ejemplos más representativos de proyectos de creación participativa que podemos vincular con el movimiento del software libre es lo que se viene a denominar habitualmente como 'cine open source', concepto de difícil definición pero que nos permite agrupar una serie de prácticas sumamente relevantes. En una primera aproximación, podemos considerar como 'cine open source' aquel realizado utilizando software libre y/o de código abierto. Es el caso del pionero corto Elephant's Dream $(2004)^{5}$, creado íntegramente por un equipo de desarrolladores - entusiastas- de la herramienta 3D Blender y que ha tenido continuidad a través de una segunda propuesta Big Buck Bunny (2008) ${ }^{6}$.

Elephant's Dream y Big Buck Bunny han tenido desde el principio una orientación colaborativa en un doble sentido: por un lado, la experimentación y la mejora técnica del programa a través de la implicación en un proyecto concreto (por tanto, con un objetivo fundamentalmente tecnológico) y por otro lado trasladando la filosofía del software libre al campo cultural, facilitando el libre acceso a los films y al proceso de producción, así como abriendo su uso: se permite y promueve no sólo la libre distribución sino también la libre reelaboración, siempre que se reconozca la autoría original y no se persigan fines comerciales.

\subsection{Formas híbridas de autoproducción audiovisual}

Una segunda aproximación nos permite observar determinadas plataformas $y$ herramientas que no encajan dentro de los principios propios del software libre pero que en cambio estimulan formas híbridas de creación colectiva y autoproducción. Un ejemplo interesante es el de la evolución de la técnica conocida bajo el nombre genérico de machinima, definida como la producción de piezas de animación utilizando como herramienta el motor de los videojuegos, identificándose su origen en el interés por parte de jugadores expertos en grabar partidas como muestra pública de su habilidad $^{7}$. La autoproducción de machinima se ha visto hasta hace relativamente poco circunscrita a la práctica del juego, hasta que la popularización de entornos virtuales como Second Life o herramientas específicas como Moviestorm ${ }^{8}$ han introducido nuevas posibilidades.

En este último caso, nos encontramos ante un programa específicamente diseñado para la creación de machinima, en el que a partir de un paquete básico de libre descarga se proporcionan personajes, escenarios, vestuario, objetos, actuaciones y situaciones para que el usuario configure y dirija accio- 
nes que son después registradas por diversas cámaras virtuales definidas también por el usuario, de forma muy similar a como se haría en una realización cinematográfica y televisiva convencional.

\subsection{Largometrajes remezclables on-line}

En una tercera aproximación, podemos considerar la adopción de estrategias colaborativas propias de la traslación de determinados principios del 'open source' a la creación audiovisual, más allá de determinadas opciones de software. Uno de los ejemplos más completos y ambiciosos lo encontramos en el proyecto británico $A$ Swarm Of Angels ${ }^{9}$, iniciado el año 2006 con el objetivo de producir un largometraje 'remezclable' de forma colaborativa, impregnando la lógica participativa a todos y cada uno de sus procesos. Partiendo de ciertas ideas conceptuales que manifiestan una afinidad temática hacia la cienciaficción distópica en la línea Matrix, se han ido impulsando diversas iniciativas productivas, como la creación de ambientes musicales (moodcasts), posters, trailers o un documental generado por los propios usuarios (autodenominados 'ángeles').

Más allá del aún en ciernes resultado final, lo más atractivo de $A$ Swarm $O f$ Angels es el proceso de creación de un modelo de producción propio, a caballo entre el liderazgo de un reducido 'núcleo creativo' y la participación colectiva de un amplio grupo de usuarios entusiastas. En este sentido, las primeras fases de $A$ Swarm Of Angels (hasta inicios de 2008), han ido fundamentalmente dirigidas a la creación de sus propios espacios, herramientas y dinámicas de comunicación y colaboración $\mathrm{y}$, progresivamente, cada vez más hacia los recursos orientados a la producción ${ }^{10}$.

\section{Conclusiones}

El recorrido precedente nos permite obtener las siguientes conclusiones sobre las implicaciones para la creciente cultura audiovisual digital de la emergencia de proyectos y estrategias de creación colectiva audiovisual on-line:

1. Los sistemas interactivos multimedia promueven la redefinición de la función-autor tradicional, al incorporar y dotar a los usuarios de las nuevas tecnologías de la información y de la comuni- cación de capacidades y dimensiones històricamente ajenas a éstos. La interactividad multimedia desdibuja y facilita así la relativización de fronteras nítidas tradicionalmente nítidas como creador versus espectador, o emisor versus receptor.

2. La colectivización que Internet y el conjunto de la cultura digital entronizan, tiene en el ámbito de la creación y de la producción audiovisual digital on- 
line a uno de sus agentes emblemáticos. En éste, asistimos a una redefinicion revolucionaria de las relaciones entre la producción, la distribución, la creación, el uso y el consumo audiovisual.

3. Los exponentes tecnológicos del movimiento por el software libre y de las iniciativas de código abierto, definen uno de los más significativos campos de experimentación contemporánea sobre el desarrollo de proyectos y estrategias emergentes de creación colectiva audiovisual.

4. El estudio de un conjunto significativo de iniciativas específicas de creación colectiva audiovisual on-line recientes, nos ha permitido caracterizar y establecer tres aproximaciones singulares, ejemplificativas de la emergencia de significativa autoría compartida y deri- vada en la cultura audiovisual digital: a) proyectos de cine open source ; b) formas híbridas de autoproducción audiovisual ; c) producciones audiovisuales remezclables.

Así, el recorrido por las herramientas y los proyectos audiovisuales colaborativos realizado expone una emergente corriente cultural en el ámbito audiovisual contemporáneo inspirada por principios próximos al movimiento del software libre y que tiene como principal objetivo establecer modelos de creación y producción audiovisual abiertos y participativos. Una cultura colaborativa on-line que establece importantes sinergias que coinciden en el establecimiento de una alternativa ética a la comercialización y al elitismo de la producción cultural en la era digital.

\section{Referencias}

ALBERICH, Jordi \& ROIG, Antoni. (2005). Comunicación audiovisual digital. Nuevos medios, nuevos usos, nuevas formas. Barcelona: Editorial UOC.

BAIGORRI, Laura \& CILLERUELO, Lourdes. (2006). Net.art (prácticas estéticas y políticas en la red). Barcelona: Editorial Brumaria.

CASACUBERTA, David. (2003). Creación colectiva. En Internet el creador es el público. Barcelona: Editorial Gedisa.

CASTELLS, Manuel. (2001). La galaxia internet. Reflexiones sobre Internet, empresa y sociedad. Barcelona: Random House Mondadori.

ECHEVERRÍA, Javier. (1999). Los señores del aire. Telépolis y el tercer entorno. Barcelona: Editorial Destino.
GUARINOS; Virginia. (2008). “ ¿Representar o simular? Esa es la pregunta. Los límites de la representación”, en Icono 14 . Revista de Comunicación audiovisual y nuevas tecnologías, Número 10. En línea:

http://www.icono14.net/revista/num10/icono14 1007.pdf $(15 / 11 / 2008)$.

HIMANEN, Pekka. (2001). La ética hacker y el espíritu del informacionalismo. Barcelona: Editorial Destino.

JENKINS, Henry. (2006). Convergence Culture. Where Old and New Media Collide. New York: New York University Press.

LANDOW, George P. (1992). Hypertext: The Convergence of Contemporary Critical Theory and Technology. Baltimore: Johns Hopkins University Press. 
LESSIG, Lawrence. (2004). Free Culture. How Big Media Uses Technology and the Law to Lock Down Culture and Creativity. New York: Penguin Books.

MUNTADAS, Antoni. (1995). 3e Biennale d'Art Contemporain de Lyon (Catálogo). París: Réunion des Musées Nationaux.

MURRAY, Janet H. (1998). Hamlet en la holocubierta. El futuro de la narrativa en el ciberespacio. Barcelona: Editorial Paidós.

RAYMOND, Eric S . (1999). The Cathedral and the Bazaar. Musings on Linux and Open Source by an Accidental Revolucionary. United States of America: O'Reilly Media.

ROIG, Antoni. (2008). "Industrias audiovisuales y nuevos medios”. En: Duran, J. y Sánchez, L. (eds.),
Industrias de la comunicación audiovisual. Barcelona: Publicaciones y ediciones de la Universitat de Barcelona.

ROIG, Antoni. (2008). Cap a al cinema col.laboratiu: pràctiques culturals i formes de producció participatives. [Tesis Doctoral, Programa de Doctorado de la Universitat Oberta de Catalunya]

STALLMAN, Richard. (2004). Software libre para una sociedad libre. Madrid: Editorial Traficantes de Sueños.

TUBELLA, Imma ; et al. (2008). Internet y Televisión: La guerra de las pantallas. Barcelona: Editorial Ariel.

\section{Notas}

${ }^{1}$ Es el caso, por ejemplo, de Kerry Conran y el film Sky Captain and the World of Tomorrow (2004).

${ }^{2}$ Muchas de estas empresas han optado por ofrecer versiones reducidas gratuitas de sus programas comerciales estándar, con la visión prospectiva que los futuros profesionales incorporen las versiones completas en sus puestos de trabajo.

${ }^{3}$ http: / / www.fsf.org/

${ }^{4}$ Conviene insistir en como la constelación de soluciones de software libre presentes en la red, resulten o no específicamente audiovisuales, se desarrollan en un permanente proceso abierto y discontinuo de redefinición y transformación, fruto de su esencial producción colaborativa en red.

${ }^{5}$ http: / / www.elephantsdream.org/

${ }^{6}$ http: / / www.bigbuckbunny.org/

${ }^{7}$ Esta primera motivación ha ido cediendo terreno a la creación específica de ficciones audiovisuales cada vez más elaboradas, hasta el punto que diferentes videojuegos como The Sims y muy particularmente The Movies han ido estimulando explícitamente la creación de machinima.

${ }^{8}$ http: / / www.moviestorm.co.uk/

${ }^{9}$ http: / / www.aswarmofangels.com/. Proyecto actualmente en standby a través de Twitter, a la espera de la puesta en marcha de su tercera fase.

${ }^{10}$ Tal y como lo refleja la experimentación con herramientas de desarrollo de guión colaborativo como Plotbot o de generación de imágenes en 3D como Motion Avatar Capture.

\section{Cita de este artículo}

Alberich Pascual, J. y Roig Telo, A. (2010). Creación colectiva audiovisual y cultura colaborativa on-line. Proyectos y estrategias Revista Icono14 [en línea] 15 de Enero de 2010, № 15. pp. 85-97. Recuperado (Fecha de acceso), de http://www.icono14.net 